\title{
EVALUATION OF PLATELET RICH FIBRIN WITH HYDROXYAPATITE CRYSTALS AS A GRAFT MATERIAL AROUND IMMEDIATE DENTAL IMPLANTS (CLINICAL AND RADIOGRAPHIC STUDY)
}

\author{
Amr Adel Abdelaty*, Tarek Abbas Hassan **, Wael Selim Amer***, \\ Tamer Abd-ElBari Hamed ${ }^{* * * *}$ and Mohamed El Shalakamy ${ }^{* * * *}$
}

\begin{abstract}
The effect of platelet rich fibrin (PRF) in association with Hydroxyapatite (HA) graft material for bony regeneration around immediate implants was studied and compared in twenty patients planned for having immediate dental implants following extraction of mandibular anterior teeth. Patients were divided into two groups. Group A In which 10 immediate implants were inserted into the extraction socket of mandibular anterior teeth and the gap around the implant was grafted with Hydroxyapatite granules. Group B In which 10 immediate implants were inserted into the extraction socket of mandibular anterior teeth and the gap around the implant was grafted with Hydroxyapatite granules associated with platelet rich fibrin (PRF). The results of this study showed that Group B showed statistically significantly higher mean bone density than Group A. We concluded that Immediate placement with delayed loading dental implants remains the procedure of choice for achieving proper Osseo integration, Immediate dental implants with HA graft material associated with PRF was significantly superior than HA graft only. PRF is a viable and biocompatible autologous biologic material, and its placement is easier and does not require a skill when compared to collagen membrane.
\end{abstract}

KEY WORDS: Platelet rich fibrin, Hydroxyapatite, Immediate dental implants.

\section{INTRODUCTION}

Misch stated that the increasing need and use of dental implants result from the combined effect of several factors ${ }^{(1)}$. Primary stability is the most important osseointegration determinant, because it allows for vital bone maintenance, clot stabilization and prevention of soft tissue collapse and epithelial down growth ${ }^{(2)}$, Zitzmann et al ${ }^{(3)}$ stated that immediate implant placement is regarded as viable

* Lecturer of Oral \& Maxillofacial Surgery, Faculty of Dentistry, British University in Egypt, Cairo. Egypt ** Professor of Oral \& Maxillofacial Surgery, Dean Faculty of Dentistry, British University in Egypt, Cairo. Egypt *** Professor of Radiology, Faculty of Dentistry, Suez Canal University, Ismailia, Egypt.

****Assistant Professor of Oral and Maxillofacial Surgery, Faculty of Dentistry, Suez Canal University, Ismailia, Egypt. 
technique, provided that proper patient selection and meticulous surgical procedures are adopted. Insertion of an implant immediately after tooth extraction offers several advantages for the patient as well as for the clinician ${ }^{(4)}$. These advantages include fewer surgical sessions and shorter rehabilitation treatment period ${ }^{(5,6)}$.

The alloplastic materials are recently used as bone substitute. They are biologically acceptable, allowing bone ingrowths and bone remodeling while maintaining volume ${ }^{(7)}$. Additionally, alloplastic materials have several advantages, such as the lack of required donor site, ample supply, and the nonexistence of disease transmission ${ }^{(8)}$. Hydroxyapatite (HA) is the major mineral component in bone, and synthetic apatite has become a common osteoconductive replacement material for bone defects ${ }^{(9)}$.

The concept of Guided tissue regeneration (GTR) is based on the exclusion of gingival connective tissue cells and prevention of epithelial down growth into the wound, thereby allowing cells with periodontal regenerative potential (PDL cells and bone cells) to enter the periodontal wound first ${ }^{(10)}$. A new supplement to procedures of tissues regeneration is represented by a platelet concentrate called PRF (Platelet-Rich Fibrin): it was tested for the first time in France by Choukroun et al ${ }^{(11)}$. PRF can regulate inflammation and to stimulate the immune process of chemotaxis. This natural material seems to accelerate the physiological wound healing; besides, in association with bone grafts, it seems to accelerate new bone formation (11). In the last years, PRF concentrates have been widely used as a supplement to tissue regeneration procedures ${ }^{(12)}$.

The successful outcome of any implant procedure requires a series of Patient related and procedure dependent parameters ${ }^{(13)}$. The volume of bone available and quality of the bone are highly associated with the type of surgical procedure and the type of implant, and both factors play a vital role in the success of dental implant surgery ${ }^{(14)}$. The American Association of Oral and Maxillofacial Radiology has stated that cross sectional views are recommended for planning dental implants, and this in combination with the easy accessibility, easy handling, and low radiation dose of CBCT imaging will lead to the widespread use of CBCT imaging in dental implantology ${ }^{(15)}$.Computerized tomography may be a useful tool for determining the bone density of interest areas before implant placement, and this valuable information about the bone quality provides dental practitioners to make better treatment planning regarding the implant positions ${ }^{(16)}$.

\section{MATERIAL AND METHODS}

This study was conducted on 20 patients planned for having immediate dental implants following extraction of mandibular anterior teeth, the gap around the inserted implants were grafted with Hydroxyapatite (HA) with or without platelet rich fibrin (PRF). The patients were selected from outpatient clinic of oral and maxillofacial surgery department, Faculty of Dentistry, Suez Canal University and Faculty of Dentistry, British University in Egypt. The age of the selected patients was ranging from 36 to 55 years with average age 47 years. The selected teeth to be replaced with immediate implants would be fractured teeth following trauma, teeth with vertical or horizontal root fracture and badly broken non-restorable tooth. Those teeth should be free from periapical pathological lesions, free from any alveolar bone damage due to trauma and should have at least $3 \mathrm{~mm}$ of sound bone present beyond the socket apices. Exclusion criteria were presence of purulent exudate at time of extraction, inadequate bone apical to extraction site, poor general health; patients with severe renal or liver diseases, history of radiotherapy in the head region, uncontrolled diabetes, recent infarction, haemophilia, bleeding 
disorders or anticoagulant therapy, metabolic disorders and signs of chronic bone disease.

\section{Preoperative evaluation}

General medical history for all patients were obtained showing free medical conditions for 16 patients and the other 4 patients was controlled diabetic. Dental histories with previous dental treatments were obtained from patients as well as any complications suffered. Oral hygiene measures, frequency of periodontal inflammation and gingival bleeding, the frequency of teeth brushing and scaling as well as the history of any treated periodontal disease. The patients were asked about a history of temporomandibular joint disorders such as clicking, muscle spasms, limitation of mouth opening, as well as the presence of abnormal oral habits as bruxism and/or clenching. A comprehensive intraoral and extra oral clinical examination based on inspection, palpation and percussion of teeth was carried out. Radiographic assessment was carried out using cone beam computed tomography (CBCT). The raw DICOM data obtained from the CBCT scanning were imported to a special third party software* for secondary reconstruction. Preoperative CBCT assessment was essential to exclude presence of pathologic bony defect, and to evaluate bone quality and the available bone volume and density.

\section{Patient grouping}

All patients were informed about detailed surgical procedure and the work started after their approval consent. Patients were divided equally into two groups, Group A (HA without PRF) and B (HA with PRF); each group consisted of ten patients, the data for each group of patients was presented in Table (1).
TABLE (1) Data about patients within group A \& B

\begin{tabular}{|l|l|c|c|}
\hline \multicolumn{2}{|c|}{ Groups } & $\begin{array}{c}\text { A } \\
(\mathbf{1 0} \text { pts. })\end{array}$ & $\begin{array}{c}\text { B } \\
(\mathbf{1 0} \text { pts. })\end{array}$ \\
\hline \multirow{2}{*}{ Sex } & Female & 6 & 7 \\
\cline { 2 - 4 } & Male & 4 & 3 \\
\hline Number of extracted teeth & 10 & 10 \\
\hline Right side & 7 & 5 \\
\hline Left side & 3 & 5 \\
\hline Unilateral cases & 9 & 9 \\
\hline Bilateral cases & \multicolumn{2}{|c|}{1} \\
\hline
\end{tabular}

Group A; (without PRF) In which 10 immediate implants were inserted into the extraction socket of mandibular anterior teeth and the gap around the implant was grafted with Hydroxyapatite (HA) granules**.

Group B; (With PRF) In which 10 immediate implants were inserted into the extraction socket of mandibular anterior teeth and the gap around the implant was grafted with Hydroxyapatite (HA) granules associated with Platelet Rich Fibrin (PRF).

\section{Operative procedures}

\section{Implant Selection}

In the current study, we used Tapered internal implant system***; Tapered Internal dental implants have tapered body, aggressive buttress threads with a deep $1.5 \mathrm{~mm}$ internal hex connection with a leadin tapered bevel for creating a rigid connection and a stable biologic seal furthermore three diameters are available $3.8,4.6,5.8 \mathrm{~mm}$ and five lengths are available $7.5,9,10.5,12,15 \mathrm{~mm}$. Determination of implant length and diameter was guided with (CBCT) data preoperatively.

\footnotetext{
* Soredex, Helsinki, Finland.

** Euro-oss, European Egyptian pharmaceutical industries, Alex, Egypt

*** Tapered Internal, BioHorizons, Birmingham, AL, USA
} 


\section{Hydroxyapatite granules for grafting procedure}

Hydroxyapatite granules with grain size 10001400 microns were used in our study, that simulates $80-85 \%$ of natural bone, possesses ill-crystalline structure, synthesized below $600^{\circ} \mathrm{C}$, and maintains strontium.

\section{Pre-surgical medications}

Two hours prior to surgery, one gm Augmentin* was given orally to the patient as a prophylactic antibiotic against infection. The patient was anesthetized using local anesthetic solution of $2 \%$ mepicaine** containing 1:20,000 levonordefrine. Nerve block anesthetic techniques were used followed by labial and lingual infiltration anesthesia to enhance hemostasis.

\section{Preparation of surgical equipment's and surgical field}

The surgical motor was adjusted to the parameters required for the operation and the accessories were connected to it, including the irrigation tubing system and sterile saline bottle. Speed reducing contra-angle hand piece (27:1) with both internal and external cooling systems was prepared and autoclaved. The surgical tray was prepared according to the predetermined implant type. Moreover, surgical tray was included hydroxyapatite graft material, sterile glass tubes, sterile plastic syringe, Centrifuge for preparation of Platelet Rich Fibrin. Extraction forceps and elevators, tissue forceps, needle holder, suture scissors, atraumatic suture needle threaded to 4-0 vicryl suture. The patients were draped in the routine manner, instructed to rinse with Betadine mouth wash, while the peri-oral skin was cleaned with surgical scrub Betadine soaked sterile gauze.

\section{Surgical procedure:}

\section{Flap design and reflection:}

Surgical Incisions were done to allow elevation of a full thickness three wall mucoperiosteal flap by a mucoperiosteal elevator to gain access and allow primary soft tissue closure.

\section{Extraction procedure}

Atraumatic surgical extraction was done starting with teeth, Miltex ${ }^{\circledR}$ Periotomes for separating the periodontal ligament thus preserved underlying bone structure, provided the necessary foundation for an implant supported replacement tooth. This is followed by using dental forceps for extraction of the planned tooth.

\section{Preparation of the implant bed and implant insertion}

The sockets were carefully debrided of soft tissue; Sequential drilling for osteotomy site with copious irrigation was carried out till the desired dimensions were achieved depending on the selected implant. After preparation of the implant site, the sealed vial enclosing the implant was removed from the non-sterile outer package by the assistant. The sterile inner vial was then slide out into the sterile operating tray. The implant was then removed from the inner vial by the operator, it was guided into the drilled site and inserted with finger rotating pressure, then the handle was detached from the implant and one end of the implant driver insert was secured to the ratchet, while the other end was seated into the implant internal hex. The ratchet handle was slowly rotated in clock wise direction threading and seating the implant into the prepared bed till its collar just sank into the alveolus with initial primary stability.

Group A; In which 10 immediate implants were inserted into the extraction socket and the gap around the implant were grafted with Hydroxyapatite (HA) granules.

Group B; In which 10 immediate implants were inserted into the extraction socket and the gap around the implant were grafted with Hydroxyapatite (HA) granules associated with Platelet Rich Fibrin (PRF).

\footnotetext{
**875mg amoxicillin and $12 \mathrm{mg}$ clavulanate potassium, GlaxoSmithKline S.A.E, El Salam city, Cairo, Egypt.
}

* Mepivecanie hydrochloride, Alex Co. Egypt. 


\section{Grafting Procedure}

Hydroxyapatite granules (HA) were grafted without platelet rich fibrin (PRF) to fill the gap around the implants for patients in group A However Ha granules associated with PRF membrane were grafted around the implants for patients in group B

\section{Platelet Rich Fibrin Preparation}

The PRF is prepared following the protocol developed by Choukroun et al. ${ }^{(11)}$ Just before surgery, intra-venous blood was collected in two $10-\mathrm{mL}$ sterile tubes without anticoagulant and immediately centrifuged in a centrifugation machine at 3,000 revolutions per minute for 10 minutes. Blood centrifugation immediately after collection allows the composition of structured fibrin clot in the middle of the tube, just between the red corpuscles at the bottom and the acellular plasma (Plateletpoor plasma) at the top Dohan et al ${ }^{(11)}$. PRF will be easily separated from red corpuscles base (preserving a small red blood cell layer) using sterile tweezers and scissors just after removal of platelet-poor plasma and then transferred onto a sterile compress then a stable fibrin membrane will be obtained by squeezing serum out of the PRF clot (Figure 1)

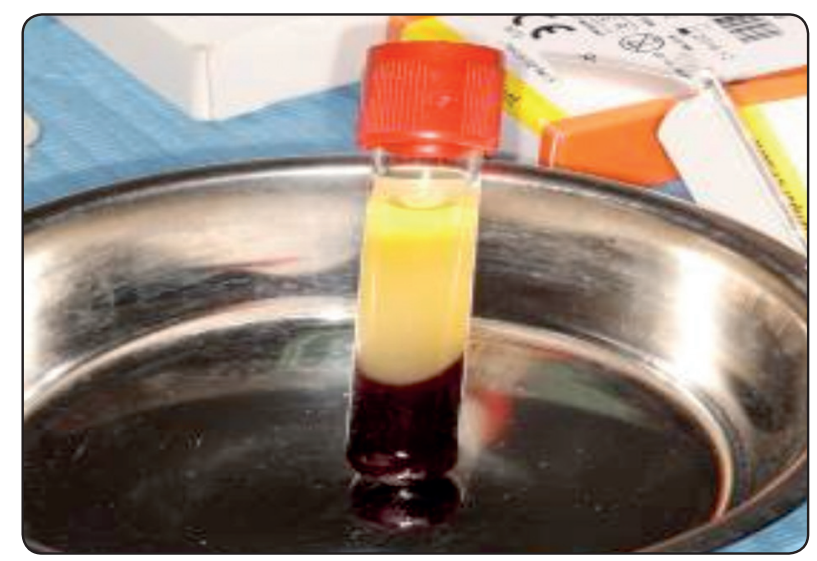

Fig. (1) Three layers formed following centrifugation

\section{Surgical wound closure}

The surgical wound was irrigated with sterile saline then the flap was repositioned back and sutured with 4-0 Vicryl suture in an interrupted fashion

\section{Post-Surgical Phase}

Augmentin* 625mg combined with Metronidazole (Flagyl)** $250 \mathrm{mg}$ t.d.s. were prescribed to all patients for one week to prevent post-surgical infection. Also, patients were instructed to rinse with $0.12 \%$ chlorohexidine gluconate mouth wash*** twice daily for 2 weeks. The patients were instructed to prevent even gentle brushing at the operated area for two weeks and In the first week post-surgically patients were asked to avoid hard and crispy food with a Recall visits scheduled every week for the first month to check the oral hygiene, and then at 3 and 6 months as a follow up. A comprehensive intraoral and extra oral physical examination was carried out through postoperative intervals.

\section{Seating abutments}

Abutments of suitable length and angulations were selected to be secured onto the implant considering seating of the abutment hex-out into the implant hex-in. The abutment screw was tightened engaging both implant and abutment as shown in (Figure 2).

Assessment of bone density in the implanted areas of the alveolar ridge was done using CBCT immediately, 3 months and 6 months postoperatively. Bone density values were collected, tabulated and statistically analyzed.

\footnotetext{
* 875mg amoxicillin and $12 \mathrm{mg}$ clavulanate potassium, GlaxoSmithKline S.A.E, El Salam city, Cairo, Egypt.

**Flagyl $\AA^{\circledR}$ by Pfizer Inc.

***Antiseptol@ by KAHIRA PHARM. \& CHEM. IND. CO..
} 


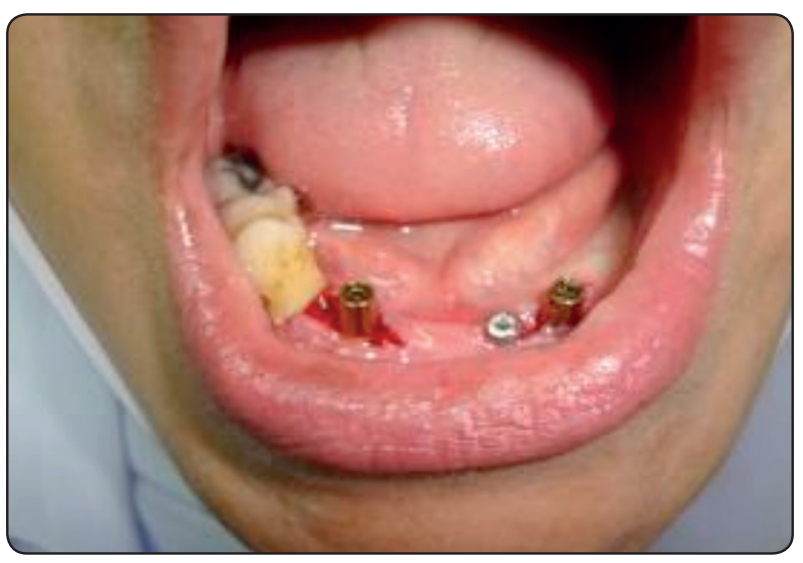

Fig. (2) Abutments seating

\section{RESULTS}

\section{Clinical results}

Postoperative healing was promising in all patients of group A and B. Soft tissue healing with healthy gingiva was observed within three weeks postoperatively. There was no pain, discomfort, tenderness, mobility or suppuration around the implants through all postoperative period. Probing depth $(\mathrm{Pd})$ were recorded in $\mathrm{mm}$ from the free gingival margin to the base of the pocket, using a periodontal probe, at six sites around each implant, the mid-facial, mid-lingual, and four mesial and distal line angles. The average of the six readings was calculated and representing the individual score of each implant. The Probing depth (Pd) values ranged from 0.3 to $2.1 \mathrm{~mm}$.

\section{Radiographic results}

Assessment of bone density was carried out for all patients at the predetermined time intervals using CBCT, A fixed size rectangular area proximal to teeth/implants was used as an area of interest for detecting bone density values as shown in (Figure 3\&4). The measurements were done by a dentist who is familiar with image analysis and did not participate in the treatment of the selected patients.

\section{Statistical results}

Numerical data were explored for normality by checking the data distribution, calculating the mean

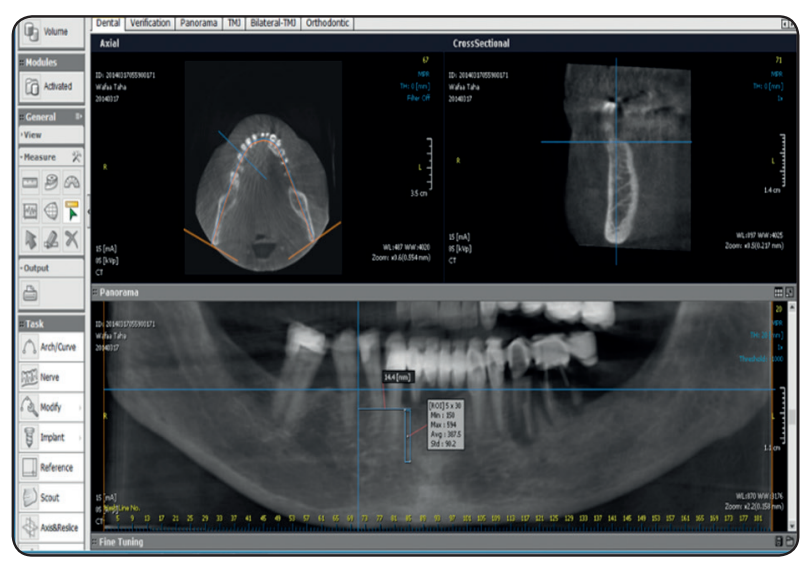

Fig. (3) Preoperative bone density measurement using CBCT.

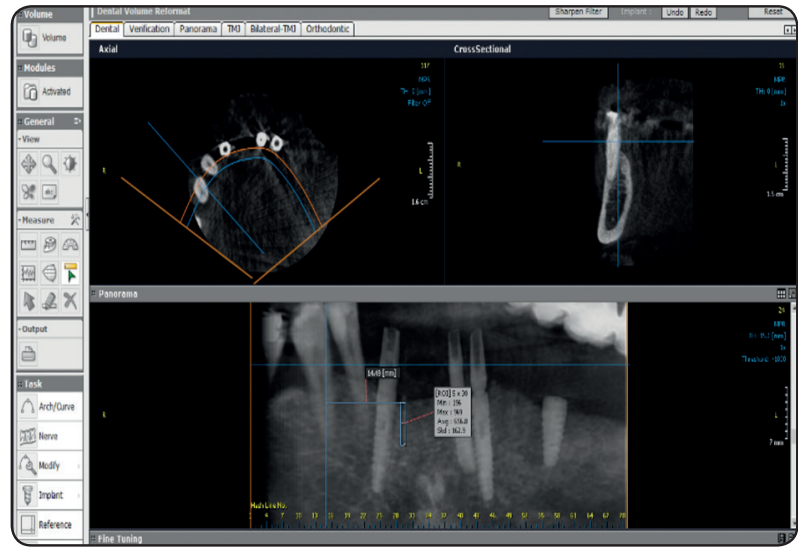

Fig. (4) Six months postoperative bone density measurement using CBCT.

and median values and using Kolmogorov-Smirnov and Shapiro-Wilk tests. Bone density data showed parametric (normal) distribution while \% increases in bone density showed non-parametric (nonnormal) distribution. Data were presented as mean and standard deviation (SD) values.

Repeated measures ANOVA test was used to study the effect of group, time, and their interactions on bone density. Bonferroni's post-hoc test was used for pair-wise comparisons when ANOVA test is significant. Mann-Whitney $U$ test was used for comparisons between \% increases in bone densities of the two groups.

Qualitative data were presented as frequencies and percentages. Chi-square $\left(x^{2}\right)$ test was used for studying the comparisons between different 
qualitative variables. The significance level was set at $\mathrm{P} \leq 0.05$. Statistical analysis was performed with IBM $^{\circledR}$ SPSS $^{\circledR}$ Statistics Version 20 for Windows.

\section{Demographic data and clinical examination}

There was no statistically significant difference between gender distributions and operated sides in both groups A and B, as shown (figure 5\&6).

\section{Bone Density:}

Repeated measures ANOVA test showed that group as well as time had statistically significant effect on mean bone density. While interaction between the two variables had no statistically significant effect on mean bone density. Since the interaction between the two variables is nonstatistically significant, so the variables' effects are independent from each other, so it is sufficient to discuss the main effects i.e. the effect of each variable regardless of the other variables as shown in table (3).

TABLE (3) Repeated measures ANOVA results for the effect of different variables on mean MIP max

\begin{tabular}{|c|c|c|c|c|c|}
\hline $\begin{array}{c}\text { Source of } \\
\text { variation }\end{array}$ & $\begin{array}{c}\text { Type III } \\
\text { Sum of } \\
\text { Squares }\end{array}$ & Df & $\begin{array}{c}\text { Mean } \\
\text { Square }\end{array}$ & $\boldsymbol{F}$-value & $\boldsymbol{P}$-value \\
\hline Group & 419302.8 & 1 & 419302.8 & 4.7 & $0.045^{*}$ \\
\hline Time & 371525.0 & 3 & 123841.5 & 100.2 & $<0.001^{*}$ \\
\hline $\begin{array}{c}\text { Group } \\
\text { x Time } \\
\text { interaction }\end{array}$ & 2954.2 & 3 & 984.7 & 0.8 & 0.501 \\
\hline
\end{tabular}

$d f:$ degrees of freedom $=(n-1), *$ : Significant at $P \leq 0.05$

\section{Comparison between both groups:}

Regardless of time Group B showed statistically significantly higher mean bone density than Group A as shown in (Figure 7).

( $\mathrm{B}$ IBM Corporation, NY, USA.

(B) SPSS, Inc., an IBM Company.

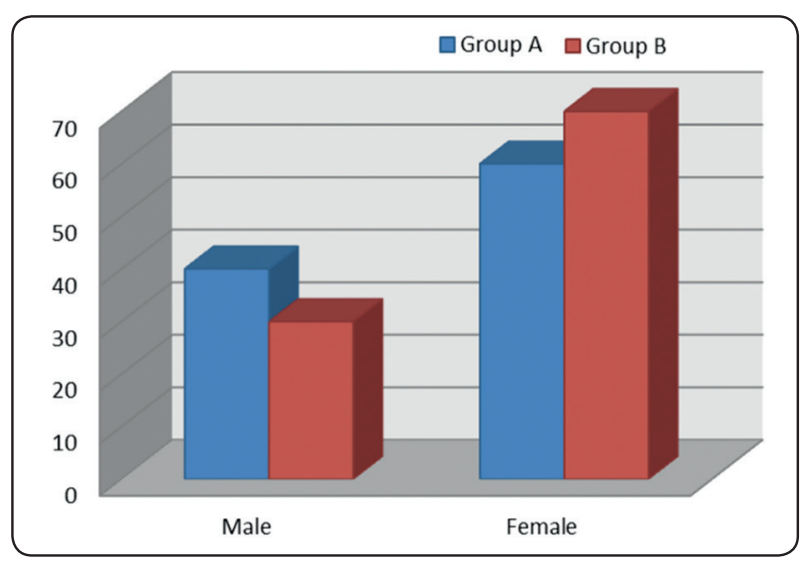

Fig.(5) Gender distributions in the two groups

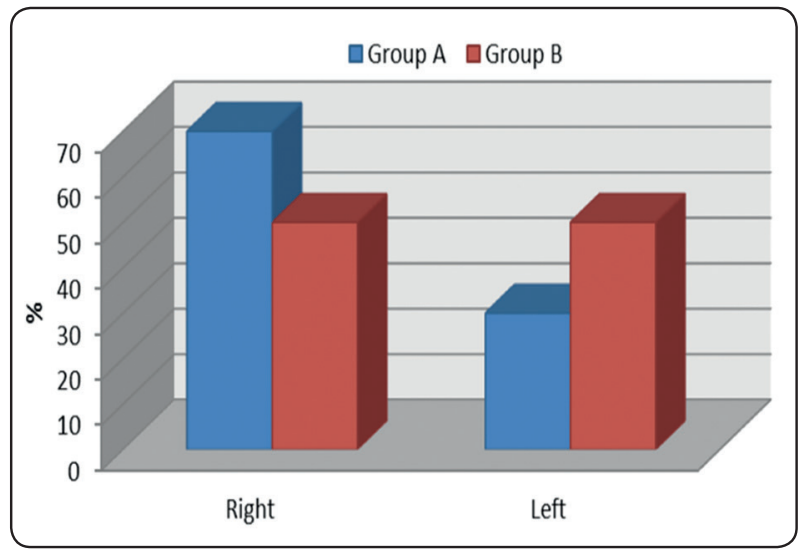

Fig.(6) Side distributions in the two groups

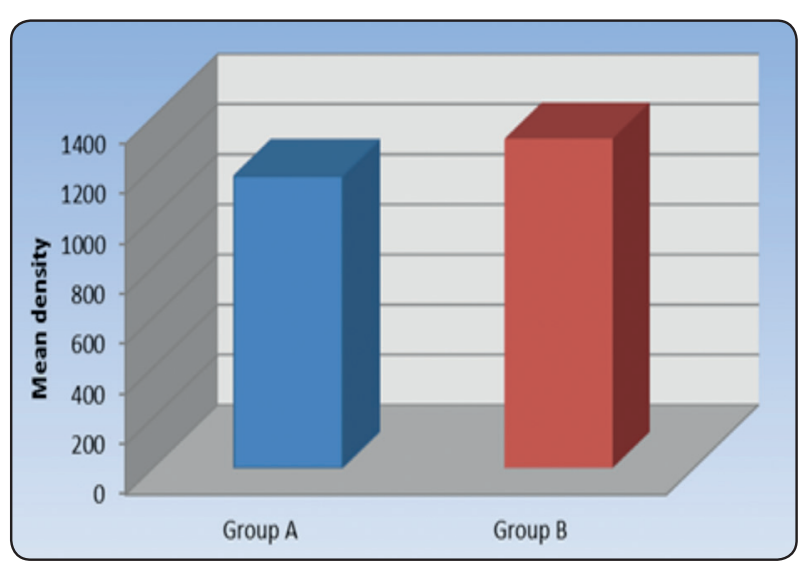

Fig. (7) Comparison between mean bone density values in the two groups regardless of time 
Pre-operatively, there was no statistically significant difference between mean bone density values in both groups However immediately postoperative, after 3 months as well as 6 months, Group B showed statistically significantly higher mean bone density than Group A as shown in (Figure 8).

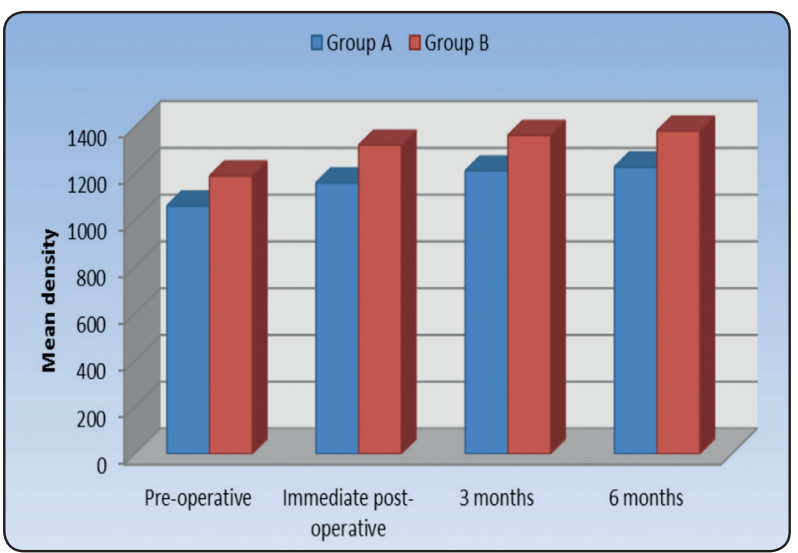

Fig. (8) Comparison between mean bone density values in the two groups at each time period

\section{Changes by time in both groups $(\mathrm{A} \& \mathrm{~B})$}

Regardless of group, there was a statistically significant increase in mean bone density immediately post-operative and after 3 months, however from 3 months to 6 months, there was no statistically significant change in mean bone density as shown in (figure 9)

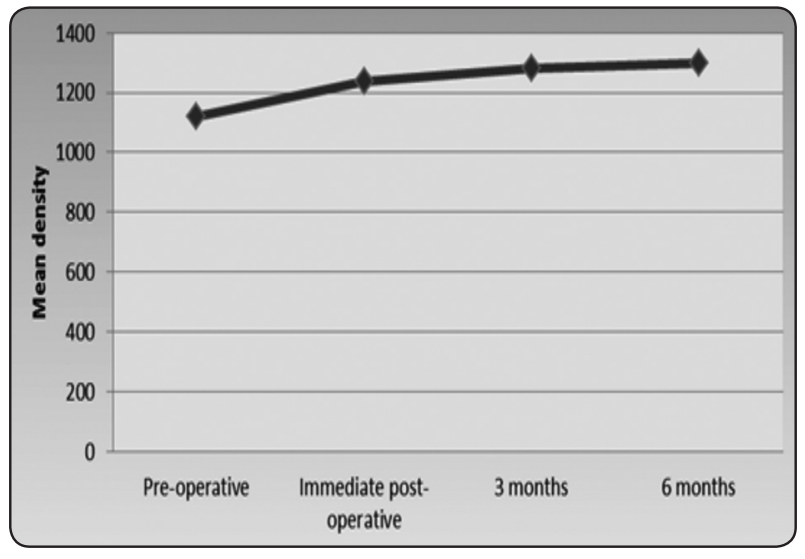

Fig.(9) Comparison between mean bone density values at different time periods regardless of group
Regarding changes occurred by time in each group, there was a statistically significant increase in mean bone density immediately post-operative and after 3 months however From 3 months to 6 months, there was no statistically significant change in mean bone density as shown in (figure 10).

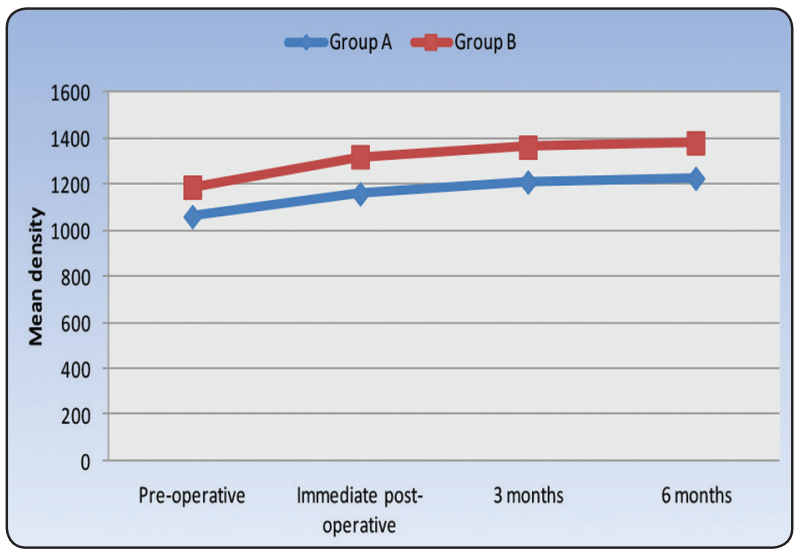

Fig. (10) Comparison between mean bone density values at different time periods in each group

Comparison between percentage changes in bone density:

The percentage change was calculated as:

Density (Pre-operative) - Density (Post-operative) x 100 Density (Pre-operative)

There was no statistically significant difference between mean percentage increases in bone density through all time periods in both groups as $\mathrm{P}$-value is 0.744 as shown in (figure 11).

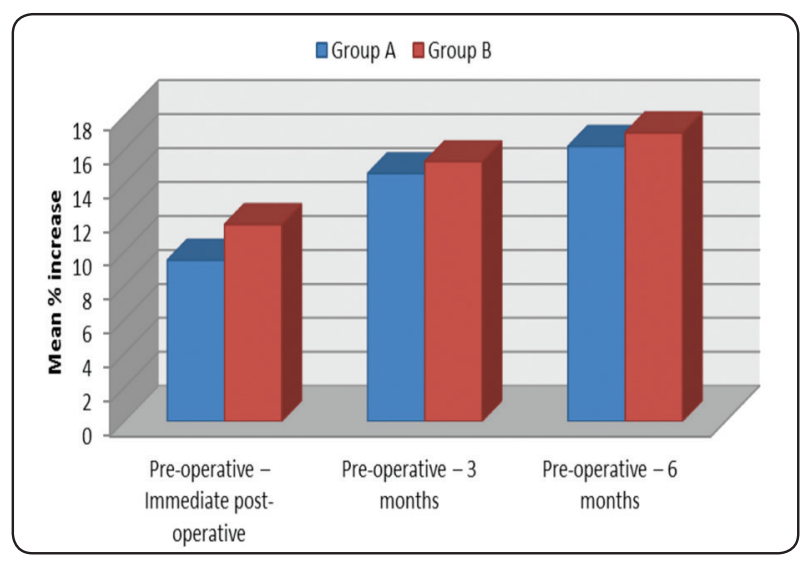

Fig. (11) Comparison between mean \% increases in bone density values of the two groups 


\section{DISCUSSION}

Immediate implant is defined as placement of the implant immediately into the fresh extraction socket ${ }^{(17-18)}$. Immediate placement of implants in fresh extraction sockets have several advantages over Branemark`s protocol for conventional implant placement; total treatment time, reduced number of surgical procedures, more ideal implant positioning and opportunities for osseointegration are better due to healing potential of fresh extraction socket ${ }^{(18)}$.

Criteria for patient selection in the current study was in agreement with Branemark et al. ${ }^{(19)}$ protocol which included atraumatic surgical procedures, good bone recipient site, load-free healing period of about 6 months, this was aimed to achieve and maintain osseointegration of dental implants. Patients in the current study were an ideal model for immediate implants that was in accordance with the study of Block and Kent ${ }^{(20)}$, who stated that indications for immediate implants were the presence of trauma, teeth with gross caries, and teeth with endodontic failure however contraindications were presence of purulent exudates and inadequate apical bone.

Patients with any medical conditions that could affect innate wound healing (21) were excluded from the study. This was in agreement with Kornman and Robertson ${ }^{(22)}$ who concluded that wound healing is a complex sequence of events including cellular and molecular interactions involving different subsets of cells, growth factors and cytokines, so any medical condition that may alter one of these components may impair and affect wound healing.

In the current study, PRF was used immediately over surgical sites based on the concept that the release of growth factors is found to be maximum at first 60 minutes and for this surgical site was exposed first before obtaining PRF in order to save time. This was in agreement with Toffler et al, (23) who also recommended using discarded fluids after squeezing the PRF clot as another source of growth factor which can be mixed with the graft materials. Furthermore, Choukroun et al., (24) suggested that addition of PRF may decrease many harmful effects of the inflammation due to the surgical procedure by correcting certain destructive and noxious excesses during healing process of wound tissues. Thus PRF could act as an immune regulation node with inflammation control abilities which explained the reduction of postoperative infection because of the presence of large number of leukocytes activated by the centrifugation in the fibrin clot, and that the PRF membranes act as fibrin bandages, enabling quick closure of the surgical sites.

In addition, the high concentration of the collected platelets in PRF allows for the slow release of growth factors from the platelet granules, allowing the PRF to be a good treatment modality in periodontal regeneration and in replacing lost tissues, resurfacing of the wounds and restoring vascular integrity ${ }^{(25)}$.

In current study defects around immediate implants were grafted with two different protocols; in group A Hydroxyapatite (HA) only was used as a graft material while in group B were grafted with Hydroxyapatite (HA) associated with platelet rich fibrin (PRF) this protocol was in accordance with Schwartz and Chaushu, ${ }^{(26)}$ who stated that a variety of regenerative techniques using combinations of bone grafts and barrier membranes have been suggested promoting bone regeneration in localized defects at implants placed into extraction sockets. Hydroxyapatite crystals were used as a graft material in both groups A \& B and this was in agreement with Paulino Castellon et al., (27) who reported that, immediate implant placement in combination with HA synthetic bone graft is a predictable procedure and provides a good bone for successful prosthetic reconstruction. Moreover, Hydroxyapatite particles have been previously evaluated in bony defects and were found to become intimately connected with adjacent bone through a crystal lattice structure at the ultrastructure level of observation ${ }^{(28,29)}$.

In the current study, radiographic assessment were done for evaluating bone density using CBCT , this was in accordance with several authors (30-35) who supported the usefulness of CBCT scans for the determination of radiographic bone density at a 
lower cost and less radiation exposure. Radiographic assessment was done to avoid evaluation of the bony changes after regenerative techniques using re-entry procedures and histological analysis as these two methods are no longer ethical and not usually accepted by the patient. Moreover, it may disturb the new connective tissue attachment and healing. Therefore, the radiographic assessment is the only non-invasive acceptable method for evaluating the changes in bone height and density following regenerative therapy ${ }^{(36-40)}$.

In the current study, the Preoperative mean bone density values in both group A \& B showed no statistically significant difference, however after 3 months as well as 6 months, group B where the gap around immediate implants was filled with HA/PRF showed statistically significant higher mean bone density than group A where gap filled with HA only. These findings were in agreement with Nobutaka Tajima et al, ${ }^{(41)}$ who stated that maxillary Sinus elevation with simultaneous implant placement using PRF as the only filling material may promote natural bone regeneration. Furthermore Ziv Mazor et al, ${ }^{(42)}$ who conducted a study on 20 patients elevating twenty-five sinus floor with simultaneous implantation using Choukroun's PRF as the sole filling biomaterial. For each patient, a pre surgical exam and a 6-month postsurgical radiologic and histomorphometric exams were done, concluded that from a radiologic and histologic point of view, the use of PRF as the sole filling material during a simultaneous sinus lift and implantation stabilized a high volume of natural regenerated bone in the sub sinus cavity up to the tip of the implant.

Consequently, We concluded that Immediate placement with delayed loading dental implants remains the procedure of choice for achieving proper osseointegration, Immediate dental implants with HA graft material associated with PRF was significantly superior than HA graft only and PRF is a viable, biocompatible autologous biologic material and its placement is easier and does not require a skill when compared to collagen membrane.

\section{REFERENCES}

1. Misch CE. Rationale for Dental Implants: In: Misch C (3rd ed). St Louis: Contemporary Implant Dentistry Elsevier Mosby, 1 (2008): 3-25.

2. McNutt M and Chou CH: Current Trends in Immediate Osseous Dental Implant Case Selection Criteria J Dent Edu, 67(8): 850-859, 2003.

3. Zitzmann, N.U., Naef, R. and Schärer, P.: Resorbable vs. nonresorbable membranes in combination with Bio Oss for guided bone regeneration. Int. J. Oral Maxillofac. Implants, 12(6): 844-52, 1997.

4. Grunder, U., Polizzi, G., Goené, R., Hatano, N., Henry, P., Jackson, J.W., Kawamura, K., Khler, S., Renouard,F., Rosenberg, R., Triplett, G., Werbitt, M. and Lithner, B.: Report on the immediate and delayed-immediate placement of implants: A 3-year prospective multicenter followup. Int. J. Oral Maxillofac. Implants, 14: 210-6, 1999.

5. Parel, S.M., and Triplett, R.G.: Immediate fixture placement: A treatment planning alternative. Int. J. Oral Maxillofac. Implants, 5(4): 337-45, 1990.

6. Lazzara, R.J.: Immediate implant placement into extraction sites: Surgical and restorative advantages. Int. J. Periodontics Restorative Dent., 9(5): 332-43, 1989.

7. Schnedel S, Bresnick S, Cholon A. Preliminary report: A ceramic containing cross linked collagen as a new cranial onlay and inlay material. Ann Plast Surg; 38: 158-162, 1997.

8. Dalkyz M, Ozcan A, Yapar M, Gokay N, Yuncu M. Evaluation of the effects of different biomaterials on bone defects. Implant Dent; 9: 226-233, 2000.

9. Lew D, Farrell B, Bardach J, Keller J. Repair of craniofacial defects with hydroxyapatite cement. J Oral Maxillofac Surg; 55: 1441-1449, 1997.

10. Wang HL \& Cooke J. Periodontal regeneration techniques for treatment of periodontal diseases. Dent Clin North Am 2005;49: 637-59.

11. Dohan DM, Choukroun J, Diss A, Dhoan SL, Dhoan AJ, Mouhyi J, Gogly B. Platelet-rich fibrin (PRF): a secondgeneration platelet concentrate. Part I: technological concepts and evolution. Oral Surg Oral Med Oral Pathol Oral Radiol Endod 2006; 101: e37-44.

12. Inchingolo F, Tatullo M, Marrelli M, Inchingolo AM, Scacco S, Inchingolo AD, Dipalma G, Vermesand, 
Abbinante A, Cagiano R. Trial with Platelet-Rich Fibrin and Bio-Oss used as grafting materials in the treatment of the severe maxillary bone atrophy: clinical and radiological evaluations. Eur Rev Med Pharmacol Sci 2010; 14: 1075-1084

13. Beer A, Gahleitner A, Holm A: Correlation of insertion torques with bone mineral density from dental quantitative CT in the mandible. Clin Oral Implants Res 2003, 14:616-620.

14. Ekfeldt, A, Christiansson, U, Eriksson, T, Lindén, U, Lundqvist, S, Rundcrantz, T: A retrospective analysis of factors associated with multiple implant failures in maxillae. Clin Oral Implants Res 2001, 12:462-467

15. Suomalainen A, Vehmas T, Kortesniemi M, Robinson S, Peltola J. Accuracy of linear measurements using dental cone beam and conventional multislice computed tomography. Dentomaxillofac Radiol 2008; 37: 10-7

16. Turkyilmaz I, Tözüm TF, Tumer C. Bone density assessments of oral implant sites using computerized tomography. J Oral Rehabil. 2007 Apr;34(4):267-72.

17. Anneroth G, Hedstorm K, Kjellman O. Endosseous titanium implants in extraction sockets. An experimental study in monkeys. Int J Oral Surg 1985;14:50-4.

18. Schwartz-Arad., Gulayev N, Chaushu G. Immediate versus non immediate implantation for full arch fixed reconstruction following extraction of all residual teeth: a retrospective comparative study. J Periodontol 2000;71:923-8.

19. Branemark PI, Hanssom BO, Adell R. Osseointegrated implants in the treatment of edentiolus jaw. J Plast Reconstr Surg 1977;11(Suppl 1-16):1-132.

20. Block MS and Kent JN. Placement of endosseaus implants, into tooth extraction sites. J Oral Maxillofac Surg 49: 1269-1276, 1991.

21. Westfelt E, Rylander H, Blohme G, Jonasson P, Lindhe J. The effect of periodontal therapy in diabetics. Results after 5 years. Journal of Clinical Periodontology.1996;23:92-100.

22. Kornman K.S. \& Robertson P.B. Fundamental principles affecting the outcomes of therapy for osseous lesions. Periodontol 2000, 2000; 22: 22-43.

23. Toffler M, Toscano N, Holtzclaw D, Corso MD, Dohan Ehrenfest DM. Introducing Choukroun's platelet rich fibrin (PRF) to the reconstructive surgery milieu. The Journal of Implant \& Advanced Clinical Dentistry 2009; 1: 21-30.
24. Dohan DM, Choukroun J, Diss A, Dohan SL, Dohan AJ, Mouhyi J, Gogly B. Platelet-rich fibrin (PRF): a second-generation platelet concentrate. Part III: leucocyte activation: a new feature for platelet concentrates? Oral Surg Oral Med Oral Pathol Oral Radiol Endod 2006; 101(3): e51-55.

25. Kang YH, Jeon SH, Park JY, Chung JH, Choung YH, Choung HW, Kim ES, Choung PH. Platelet-rich fibrin (PRF) is a bioscaffold and reservoir of growth factors for tissue regeneration. Tissue Engineering; 17: 349-359, 2011.

26. Schwartz-Arad D, \& Chaushu G. The ways and wherefores of immediate placement of implants into fresh extraction sites: a literature review. J Periodontol 68:915-23 (1997).

27. Paulino Castellon D, Raymond A \& Yukna DMD. Immediate dental implant placement in sockets augmented with HTR synthetic bone. Implant Dent 13: 42-48 (2004).

28. Jarcho M: Calcium phosphate ceramics as hard tissue prosthetics. Clin Orthop 157:259, 1981

29. Tracy BM, Doremus RH: Direct electron microscopy studies of the bone hydroxylapatite interface. J Bio Med Mat Res 18:719, 1984

30. Chun YS, Lim WH. Bone density at interradicular sites: implications for orthodontic mini-implant placement. Orthod Craniofac Res 2009;12:25-32.

31. Noujeim M, Prihoda T, Langlais R, Nummikoski P. Evaluation of high-resolution cone beam computed tomography in the detection of simulated interradicular bone lesions. Dentomaxillofac Radiol 2009;38:156-162.

32. Miracle AC, Mukherji SK. Conebeam CT of the head and neck, part 2: clinical applications. AJNR Am J Neuroradiol 2009;30:1285-1292

33. Scarfe WC, Farman AG, Sukovic P. Clinical applications of cone beam computed tomography in dental practice. $\mathrm{J}$ Can Dent Assoc 2006;72:75-80

34. Simon JH, Enciso R, Malfaz JM, Roges R, Bailey-Perry M, Patel A. Differential diagnosis of large periapical lesions using cone beam computed tomography measurements and biopsy. J Endod 2006;32:833-837.

35. Turkyilmaz I, McGlumphy EA. Influence of bone density on implant stability parameters and implant success: a retrospective clinical study. BMC Oral Health 2008;8:32.

36. Parashis AO, Anagnou A. \& Demetriou N. Calculus removal from multirooted teeth with and without surgical 
access. I. Efficacy on external and furcation surfaces in relation to probing depth. J Clin Periodontol, 1993a; 20: 63-68.

37. Parashis AO, Anagnou A. \& Demetriou N. Calculus removal from multirooted teeth with and without surgical access. I. Efficacy on external and furcation surfaces and effect of furcation entrance width. J Clin. Periodontol, 1993b; 20: 294-298.

38. Ron Zohar \& Howard C. Tenenbaum. How peridectable are periodontal regenerative procedures? J Can Dent Assoc. 2005; 71(9): 675-680.

39. Minenna L, Herrero F, Sanz M and Trombelli L. Adjunctive effect of a polylactide/polyglycolide copolymer in the treatment of deep periodontal intra-osseous defects. A randomized clinical trial. J Clin Periodontol, 2005; 32: 456-461.
40. Kanakamedala A, Ari G, Sudhakar U, Vijayalakshmi R, Ramakrishnan $\mathrm{T}$ and Emmadi P. Treatment of a furcation defect with a combination of platelet-rich fibrin (PRF) and bone graft- a case report. Endo (Lond Engl) 2009; 3(2): 127-135.

41. Nobutaka Tajima, Seigo Ohba, Takashi Sawase, Izumi Asahina, Evaluation of Sinus Floor Augmentation with Simultaneous Implant Placement Using Platelet-Rich Fibrin as Sole Grafting Material Int J Oral Maxillofac Implants 2013;28:77-83.

42. Ziv Mazor, Robert A. Horowitz, Marco Del Corso, Hari S. Prasad, Michael D. Rohrer and David M. Dohan Ehrenfesti. Sinus Floor Augmentation With Simultaneous Implant Placement Using Choukroun's Platelet-Rich Fibrin as the Sole Grafting Material: A Radiologic and Histologic Study at 6 Months J Periodontol 2009;80:2056-2064. 